\title{
Spontaneous Corneal Clearance in the Presence of a Partially Detached Graft after Non-Descemet Stripping Automated Endothelial Keratoplasty
}

\author{
Konstantinos Droutsas ${ }^{\mathrm{a}-\mathrm{c}} \quad$ Apostolos Lazaridis $^{\mathrm{a}, \mathrm{c}}$ \\ Chrysanthi Koutsandrea $^{c} \quad$ Klio I. Chatzistefanou ${ }^{c}$ Marilita M. Moschos ${ }^{c}$ \\ Walter Sekundo ${ }^{\mathrm{a}}$ \\ ${ }^{a}$ Department of Ophthalmology, Philipps University, Marburg, Germany; ${ }^{b}$ The Netherlands \\ Institute for Innovative Ocular Surgery, Rotterdam, The Netherlands; ${ }^{C}$ First Department of \\ Ophthalmology, National and Kapodistrian University of Athens, Medical School of \\ Athens, Athens, Greece
}

\section{Key Words}

Spontaneous corneal clearance $\cdot$ Non-Descemet stripping automated endothelial keratoplasty $\cdot$ Contact inhibition

\begin{abstract}
Purpose: To report the explantation of a detached and opaque donor disc as an alternative to secondary keratoplasty in a case of persistent graft detachment followed by spontaneous clearance of the recipient cornea after non-Descemet stripping automated endothelial keratoplasty (non-DSAEK). Methods: A 57-year-old man with cataract and bullous keratopathy after herpes simplex virus endotheliitis of the right eye and best spectacle-corrected visual acuity (BSCVA) of 0.1 underwent simultaneous phacoemulsification and non-DSAEK. Due to early detachment of the donor disc, two additional intracameral air injections were necessary in order to achieve graft attachment. However, the donor disc gradually detached and became fibrotic while the recipient cornea anterior to the detached graft became transparent and without any edema. Therefore, a mere explantation of the DSAEK graft was performed. Results: Four months after graft explantation, BSCVA was 0.5 and endothelial cell density (ECD) was 1,221 cells $/ \mathrm{mm}^{2}$. After 13 months, BSCVA was still 0.6 while ECD had fell to 800 , and 2 years later, the endothelium decompensated. BSCVA was 0.3 and ECD was not measurable. Conclusions: To our knowledge this is the first report of explantation of an endothelial graft as an alternative to re-keratoplasty in a case of spontaneous corneal clearance. This
\end{abstract}

\section{KARGER}

Konstantinos Droutsas, MD

First Department of Ophthalmology

National and Kapodistrian University of Athens

Mesogeion Av. 154, GR-11527 Athens (Greece)

E-Mail konstantinos_droutsas@yahoo.gr 
minimally invasive treatment may be considered in similar cases. However, due to the ongoing loss of endothelial cells after endothelial keratoplasty, a re-keratoplasty may still be needed in the long term.

(C) 2016 The Author(s)

Published by S. Karger AG, Basel

\section{Introduction}

Endothelial keratoplasty (EK) combines fast visual rehabilitation and a low risk profile and has therefore replaced penetrating keratoplasty in the treatment of corneal endothelial diseases $[1,2]$. The concept of EK is based on the creation of a (nearly) normal corneal anatomy by positioning a donor disc comprising endothelium and Descemet membrane (DM) (DM endothelial keratoplasty, DMEK) or endothelium, DM and posterior stroma (Descemet stripping automated endothelial keratoplasty, DSAEK) onto the back surface of the recipient cornea [3].

Graft detachment is a major cause of failure of EK procedures. Rarely, the recipient cornea may clear within several weeks to months after EK despite the presence of a detached graft [4-10]. The exact mechanism of spontaneous corneal clearance remains unknown.

Descemetorhexis, which is the removal of the central portion of the recipient's endothelium and DM, is routinely performed in EK procedures; it is considered a crucial surgical step which facilitates donor attachment and promotes endothelial cell migration by disrupting the intercellular contact inhibition [11]. Especially guttae as seen in Fuchs endothelial dystrophy (FED) may interfere with the visual result and should therefore be removed during EK. In bullous keratopathies not associated with guttae, however, DM may be left in situ (non-DSAEK). Thus, the procedure is simplified and surgical time is reduced $[12,13]$.

In the present report, we describe a case of spontaneous corneal clearance after nonDSAEK in the presence of a detached and fibrotic donor disc which was treated by the explantation of the graft.

\section{Case Report}

A 57-year-old man was referred for EK due to bullous keratopathy after recurrent herpetic endotheliitis of his right eye (OD). He complained about progressive vision loss and glare for 14 months and also reported having received oral acyclovir during the previous 12 months with no improvement. Best spectacle-corrected visual acuity (BSCVA) was 0.1 OD and 1.2 in the left eye. Biomicroscopy revealed central stromal edema, a small paracentral postinfectious subepithelial scar and a grade $1+$ nuclear cataract. The patient was scheduled for phacoemulsification combined with non-DSAEK. The DM of the host was not removed in order to avoid a possible reactivation of the herpetic endotheliitis by the additional trauma. Prophylaxis with oral acyclovir $800 \mathrm{mg}$ three times daily was carried out during the perioperative period.

After subtenon's anesthesia, phacoemulsification was performed and a three-piece intraocular lens was inserted into the capsular bag. For non-DSAEK, a precut graft with an endothelial cell density (ECD) of 2,528 cells $/ \mathrm{mm}^{2}$ was used. First, a $4.5-\mathrm{mm}$ limbal tunnel was created nasally. The donor tissue was trephined to a diameter of $8.5 \mathrm{~mm}$, positioned on a Busin glide (Moria, Antony, France) and inserted into the anterior chamber with the pullthrough technique after Busin et al. [14]. After suturing all incisions, air was injected underneath the donor disc until a complete air fill of the anterior chamber. Entrapped interface 
fluid was removed through four paracentral vent incisions. After $2 \mathrm{~h}$, a small amount of air was released at the slit lamp in order to relieve the air-induced pupillary block. In the following hours, the patient had difficulty to maintain supine positioning due to obesity-related orthopnea. During the first postoperative days, the donor disc detached and re-attached after two intracameral air injections (fig. 1).

In the following weeks, however, the donor disc gradually became fibrotic and detached starting at its inferonasal periphery. Due to a poor BSCVA of only $0.1(+1.50 \mathrm{sph}-1.25 \mathrm{cyl}$ $\times 3^{\circ}$ ), the patient was scheduled for a repeat endothelial keratoplasty. Five months after the initial procedure, BSCVA was $0.05\left(+1.75 \mathrm{sph}-1.25 \mathrm{cyl} \times 3^{\circ}\right)$ and the donor disc was subtotally detached and opaque (fig. 2a, b). Strikingly, the patient's own cornea was transparent with a corneal thickness of $595 \mu \mathrm{m}$ and an ECD of 1,251 cells $/ \mathrm{mm}^{2}$. We therefore suggested a mere explantation of the fibrotic donor disc without secondary implantation of a new graft.

The explantation of the donor disc was performed under subtenon's anesthesia. The anterior chamber was filled with viscoelastic (sodium hyaluronate 1\%; Provisc, Alcon Laboratories, Inc., Fort Worth, Tex., USA), an inferotemporal 3.5-mm incision was created and the graft was removed with fine-toothed forceps from the anterior chamber. After removal of the viscoelastic the tunnel was sutured.

The postoperative treatment regimen consisted of tobramycin and dexamethasone eye drops 6 times daily for 1 week and then prednisolone acetate 1\% 4 times daily for 3 weeks and then decreased by one drop every 3 months. Topical prednisolone acetate $1 \%$ once daily was then continued infinitely. In addition, the patient received prophylactic treatment with $400 \mathrm{mg}$ of oral acyclovir 2 times daily for the following 12 months. At 1 month, the sutures were removed (fig. 2c, d). Four months after explantation, BSCVA was $0.5(+1.5 \mathrm{sph}-0.5 \mathrm{cyl}$ $\left.\times 169^{\circ}\right)$ and ECD was 1,221 cells $/ \mathrm{mm}^{2}$. At 7 months, BSCVA was $0.6\left(+2.0 \mathrm{sph}-3.5 \mathrm{cyl} \times 10^{\circ}\right)$ and ECD was 1,181 cells $/ \mathrm{mm}^{2}$. After 13 months, BSCVA was still $0.6\left(+1.5 \mathrm{sph}-3.5 \mathrm{cyl} \times 10^{\circ}\right)$; however, ECD had decreased at 800 cells $/ \mathrm{mm}^{2}$. At 25 months, BSCVA was $0.3(+0.5 \mathrm{sph})$, ECD was not measurable and corneal thickness and densitometry had increased (table 1).

Central corneal thickness as measured by Scheimpflug tomography (Pentacam HR, Oculus, Wetzlar, Germany) decreased from 595 to $496 \mu \mathrm{m}$ in the first month after removal of the donor disc and gradually increased to $554 \mu \mathrm{m}$ at 25 months (fig. 3a-d).

\section{Discussion}

To our knowledge, this is the first report of spontaneous corneal clearance after nonDSAEK in the presence of a fibrotic and subtotally detached donor disc obscuring the visual axis. Instead of a repeat keratoplasty, the mere removal of the donor disc led to a significant increase in visual acuity, reduction of corneal thickness and improvement of corneal clarity for a significant period of time.

In EK, corneal anatomy is restored by placing a donor lamella consisting of functional endothelium and DM (DMEK) or endothelium, DM and posterior stroma (DSAEK) onto the posterior surface of the recipient cornea. Detachment of the donor tissue leads to edema of the exposed recipient stroma and is a major cause of graft failure in EK.

However, recent clinical observations of spontaneous corneal clearance in the presence of a detached graft have challenged this concept. Zafirakis et al. [4] described a case of a clear cornea despite corneal graft detachment 9 months after DSAEK. Balachandran et al. [5] reported two cases of spontaneous clearance in the presence of a (sub)total graft detachment. Ham et al. [6] described a case of edema due to FED where the surgery had to be aborted after completion of descemetorhexis and the cornea did not clear. Arbelaez et al. [7] report- 
ed on three cases of edema due to FED where mere descemetorhexis led only to subtotal clearing of the host cornea. Shah et al. [8] described a case of clearance after descemetorhexis without graft placement in a case of FED and posterior polymorphous dystrophy.

Dirisamer et al. $[9,10]$ examined the question whether the repopulating cells stem from the host or donor endothelium in a case series of DM endothelial transfer, which is the insertion of a free-floating DM endothelial graft in the anterior chamber after descemetorhexis. They observed that corneas with FED cleared, whereas the endothelial graft did not have an effect in eyes with bullous keratopathy.

Descemetorhexis is routinely performed in DSAEK and DMEK procedures. This maneuver increases donor tissue adherence on the inner surface of the recipient cornea, which might be inhibited in the presence of the recipient endothelium. Moreover, it creates a circular front of contact inhibition loss in the endothelial monolayer, which is thought to facilitate centripetal endothelial cell migration.

In this particular case, descemetorhexis was avoided in order to prevent a reactivation of the endotheliitis. Nevertheless, the condition of contact inhibition disruption could have been satisfied, as the endothelium in the center of the recipient cornea had been probably damaged due to its sandwiching in the host-donor interface. Moreover, the gradual graft detachment exposed the host's DM, upon which functional host, donor or both host and donor cells may have migrated. In addition, the presence of donor tissue in our case may have also induced proliferation of recipient endothelium in a paracrine fashion by releasing cytokines and mitogenic growth factors in the aqueous humor as a response to the surgical trauma [15]. In addition, since the patient had undergone a long-term antiherpetic treatment without any improvement, a functional recovery of host endothelium due to the perioperative acyclovir course is unlikely.

The new endothelial monolayer maintained its functional integrity over a period of 2 years. Although the endothelial loss after graft explantation was similar to the one reported after EK procedures, one may assume additional pathomechanisms involved in the continuous decline of ECD, e.g. a chronic subclinical endotheliitis triggered by herpes simplex virus reactivation or immunologic rejection of donor endothelial cells located on the posterior surface of the recipient cornea [16].

In summary, this is to our knowledge the first report of spontaneous corneal clearance after non-DSAEK. In similar cases with a detached and fibrotic graft obscuring the visual axis, the mere explantation of the graft may restore vision in the medium term, thus postponing further keratoplasty procedures. In our case, the duration of the good visual outcome was probably limited by the low baseline ECD; however, a subclinical endotheliitis cannot be ruled out as an additional factor of endothelial damage.

\section{Statement of Ethics}

The authors have no ethical conflicts to disclose.

\section{Disclosure Statement}

The authors have nothing to disclose. 
Case Reports in

Ophthalmology

\begin{tabular}{l|l|}
\hline Case Rep Ophthalmol 2016;7:321-327 \\
\hline DOI: 10.1159/000443632 & $\begin{array}{l}\text { ○ } 2016 \text { The Author(s). Published by S. Karger AG, Basel } \\
\text { www.karger.com/cop }\end{array}$ \\
\hline
\end{tabular}

Droutsas et al.: Spontaneous Corneal Clearance in the Presence of a Partially Detached Graft after Non-Descemet Stripping Automated Endothelial Keratoplasty

\section{References}

1 Dapena I, Ham L, Melles GR: Endothelial keratoplasty: DSEK/DSAEK or DMEK - the thinner the better? Curr Opin Ophthalmol 2009;20:299-307.

2 Cursiefen C: Descemet membrane endothelial keratoplasty: the taming of the shrew. JAMA Ophthalmol 2013;131:88-89.

3 Melles GR: Posterior lamellar keratoplasty: DLEK to DSEK to DMEK. Cornea 2006;25:879-881.

$\checkmark 4$ Zafirakis P, Kymionis GD, Grentzelos MA, Livir-Rallatos G: Corneal graft detachment without corneal edema after Descemet stripping automated endothelial keratoplasty. Cornea 2010;29:456-458.

$\longrightarrow 5$ Balachandran C, Ham L, Verschoor CA, Ong TS, van der Wees J, Melles GR: Spontaneous corneal clearance despite graft detachment in Descemet membrane endothelial keratoplasty. Am J Ophthalmol 2009;148:227-234.

6 Ham L, Dapena I, Moutsouris K, Melles GR: Persistent corneal edema after descemetorhexis without corneal graft implantation in a case of Fuchs endothelial dystrophy. Cornea 2011;30:248-249.

-7 Arbelaez JG, Price MO, Price FW: Long-term follow-up and complications of stripping Descemet membrane without placement of graft in eyes with Fuchs endothelial dystrophy. Cornea 2014;33:1295-1299.

-8 Shah RD, Randleman JB, Grossnikalus HE: Spontaneous corneal clearing after Descemet's stripping without endothelial replacement. Ophthalmology 2012;119:256-260.

-9 Dirisamer M, Ham L, Dapena I, van Dijk K, Melles GR: Descemet membrane endothelial transfer: 'freefloating' donor Descemet implantation as a potential alternative to 'keratoplasty'. Cornea 2012;31:194-197.

10 Dirisamer M, Yeh RY, van Dijk K, Ham L, Dapena I, Melles GR: Recipient endothelium may relate to corneal clearance in Descemet membrane endothelial transfer. Am J Ophthalmol 2012;154:290-296.

-11 Melles GR, Wijdh RH, Nieuwendaal CP: A technique to excise the Descemet membrane from a recipient cornea (descemetorhexis). Cornea 2004;23:286-288.

12 Kobayashi A, Yokogawa H, Sugiyama K: Non-Descemet stripping automated endothelial keratoplasty for endothelial dysfunction secondary to argon laser iridotomy. Am J Ophthalmol 2008;146:543-549.

13 Chaurasia S, Ramappa M, Sangwan VS: Clinical outcomes of non-Descemet stripping automated endothelial keratoplasty. Int Ophthalmol 2012;32:571-575.

-14 Busin M, Bhatt PR, Scorcia V: A modified technique for Descemet membrane stripping automated endothelial keratoplasty to minimize endothelial cell loss. Arch Ophthalmol 2008;126:1133-1137. Joyce NC: Proliferative capacity of the corneal endothelium. Prog Retin Eye Res 2003;22:359-389. Dooren BT, Saelens IE, Bleyen I, Mulder PG, Bartels MC, Rij GV: Endothelial cell decay after Descemet's stripping automated endothelial keratoplasty and top hat penetrating keratoplasty. Invest Ophthalmol Vis Sci 2011;52:9226-9231.

Table 1. Visus, endothelial cell density and corneal parameters before and after graft explantation

\begin{tabular}{lllll}
\hline Examination & BSCVA & $\begin{array}{l}\text { ECD, } \\
\text { cells/mm }{ }^{2}\end{array}$ & $\begin{array}{l}\text { Pachym- } \\
\text { etry, } \mu \mathrm{m}\end{array}$ & $\begin{array}{l}\text { Densitom- } \\
\text { etry, GSU }\end{array}$ \\
\hline Prior to GE & 0.05 & 1,251 & 595 & 40.9 \\
$\quad 4$ months after GE & 0.5 & 1,221 & 483 & 35.0 \\
7 months after GE & 0.6 & 1,181 & 500 & 33.4 \\
13 months after GE & 0.6 & 800 & 535 & 35.2 \\
25 months after GE & 0.3 & NM & 555 & 38.5 \\
\hline
\end{tabular}

$\mathrm{GE}=$ Graft explantation; GSU = grayscale units; $\mathrm{NM}=$ not measurable. 
Case Reports in

Ophthalmology

\begin{tabular}{l|l}
\hline Case Rep Ophthalmol 2016;7:321-327 \\
\hline DOI: 10.1159/000443632 & $\begin{array}{l}\text { @ } 2016 \text { The Author(s). Published by S. Karger AG, Basel } \\
\text { www.karger.com/cop }\end{array}$ \\
\hline
\end{tabular}
www.karger.com/cop

Droutsas et al.: Spontaneous Corneal Clearance in the Presence of a Partially Detached Graft after Non-Descemet Stripping Automated Endothelial Keratoplasty
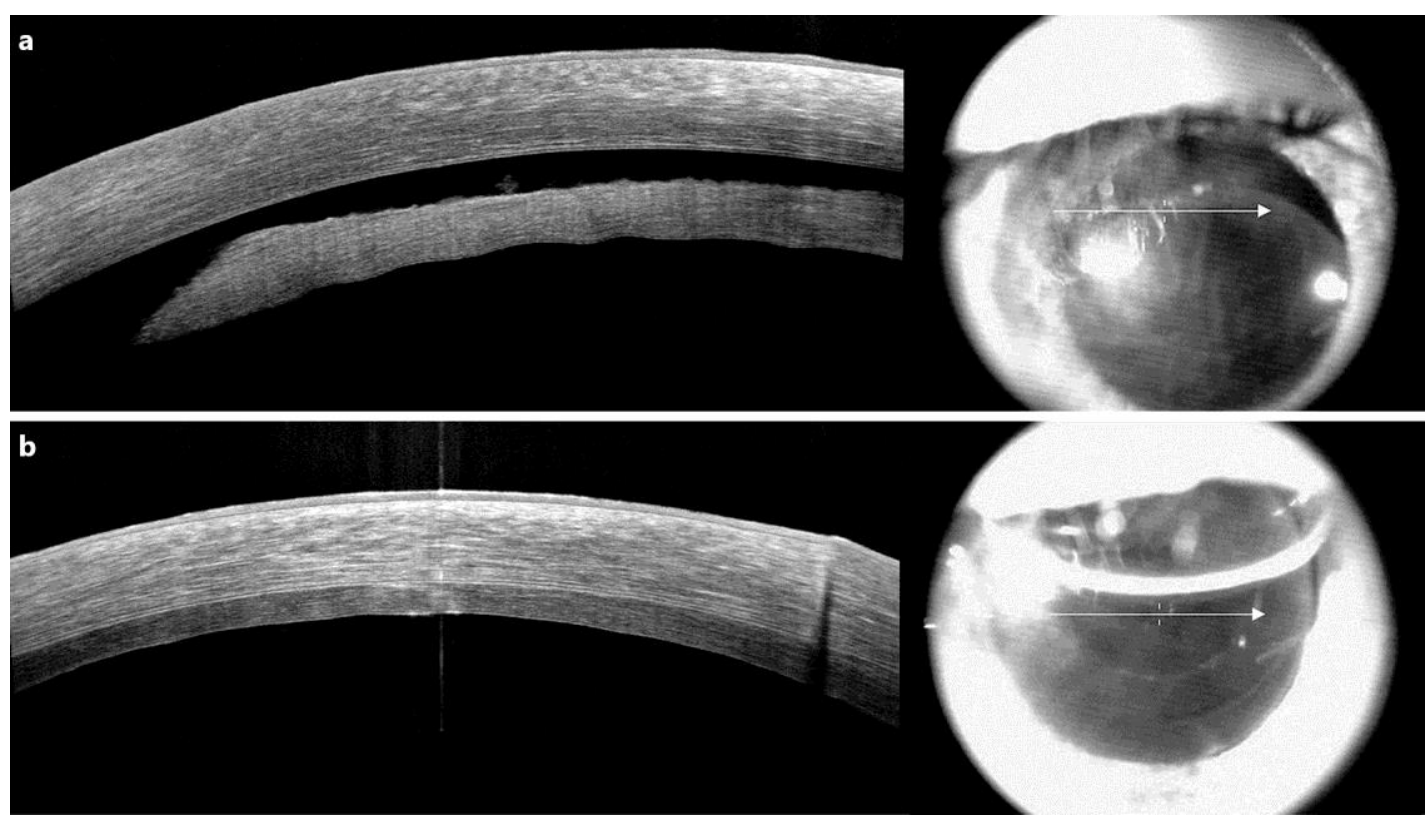

Fig. 1. Optical coherence tomography showing the detached and edematous donor disc after non-DSAEK (a), which reattached after two rebubbling procedures (b).
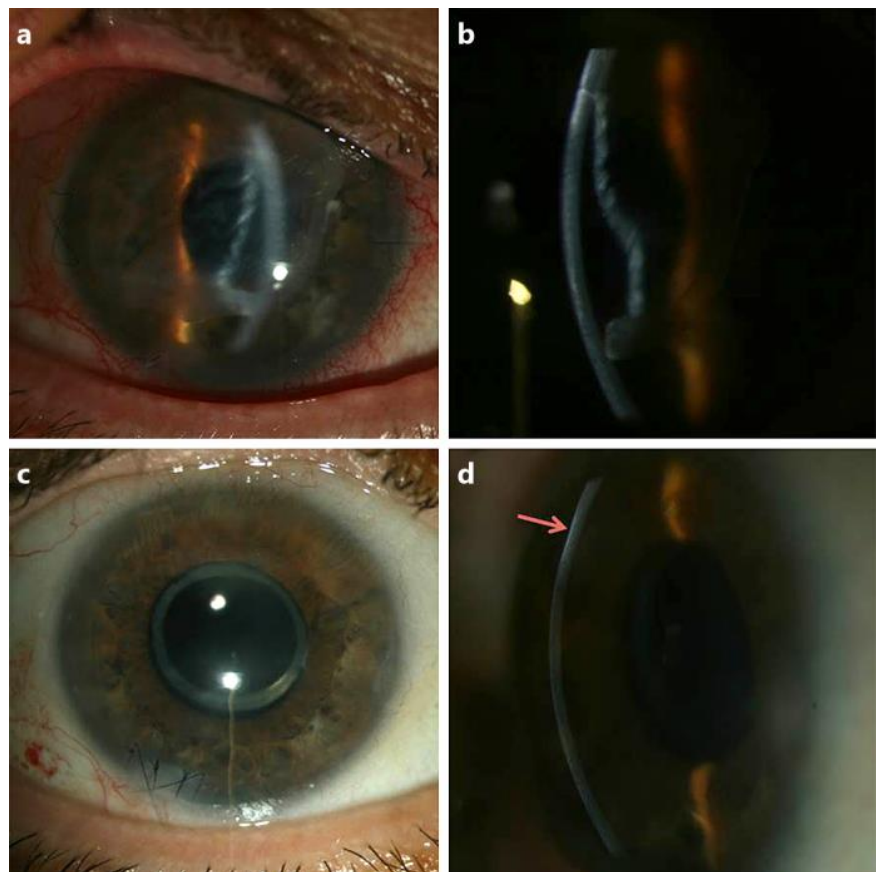

Fig. 2. Slit-lamp pictures of the detached and fibrotic donor disc. Please note that the patient's cornea appears transparent and nonedematous $(\mathbf{a}, \mathbf{b})$. One month following the explantation of the detached graft, the cornea has a nearly normal appearance at the slit lamp (c, d) except for a superficial postinfectious scar (pink arrow). 
Droutsas et al.: Spontaneous Corneal Clearance in the Presence of a Partially Detached Graft after Non-Descemet Stripping Automated Endothelial Keratoplasty
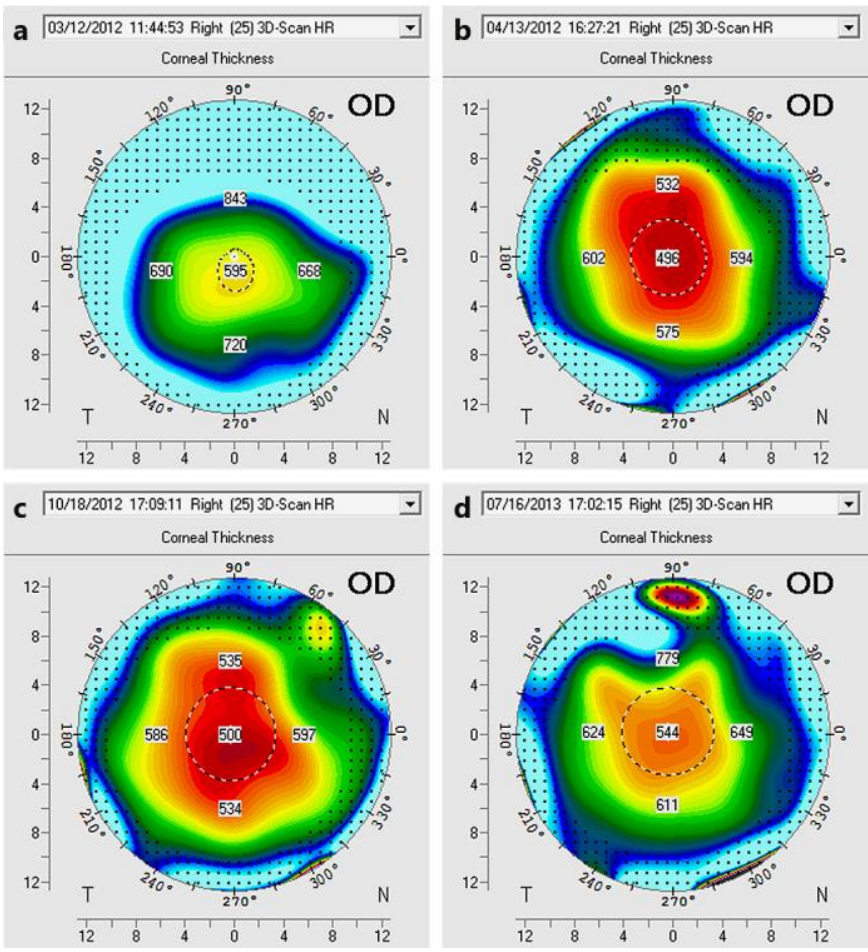

Fig. 3. Scheimpflug pachymetry maps displaying corneal thickness before (a) and at 1 (b), 7 (c) and 16 months (d) after graft explantation. Please note that corneal thickness increased between month 7 and 16, indicating a subclinical endothelial dysfunction. 